\title{
The Effect of Electrolytic Capacitors on SMPS's Failure Rate
}

\author{
B. Abdi, R. Ghasemi, and S. M. M. Mirtalaei, Member, IACSIT
}

\begin{abstract}
Recently, reliability is one of the serious requirements of electronic systems. The numbers of system failures, repair cost, guarantee and etc are estimated by reliability prediction. In this paper, the reliability of a switching power supply, which is used for personal computers, evaluates. It will show that electrolytic capacitors, used in input and output filters, play a significant role on the computer's power supply's life time. Ambient temperature, derating, and capacitance effect on the failure rate will discuss. The remedies are recommended for more life time.
\end{abstract}

Index Terms-Electrolytic capacitor, reliability, SMPS, PC.

\section{INTRODUCTION}

Switch Mode Power Supplies (SMPSs) are used in Personal Computers (PCs), because of their high efficiency and low volume and weight. SMPSs are used in all PCs for convert the voltage to different levels and establish it against input voltage and load variations [1].

The efficiency of joinery SMPSs, are used in PCs, is about $70 \%$ and all the power consumption of PC produced by subsystem. So they are the most critical point of PCs from reliability lookout and almost $90 \%$ of PC failures belong to their SMPSs.

Lifetime and failure rate of a system can be predicted by reliability calculations. Recently, reliability became to a prevalent issue in power electronic systems. The effect of transformer leakage inductance on SMPSs reliability is discussed in [2]. The effect of equivalent series resistance of capacitors on the reliability of SMPSs is presented in [3]. Reliability modification of power electronic converter for full cell and photovoltaic application are discussed [4]-[6]. Dissertation of operating mode (continuous and discontinuous modes) with aim of reliability, for SMPSs, presented in [7] and using a single integrated power module (IPM) instead of paralleling power electronic devices are given in [8].

The method of reliability calculation, for a PC's SMPS, is presented, and the most critical points are introduced in previous work [9]. It is shown that electrolytic capacitors have a major role in the SMPS's reliability.

AC voltage is converted to DC via a rectifier and a bulk capacitor in the input stage of a SMPS. At the output stage of SMPSs, usually, an LC filter, which is composed of an inductor and a capacitor, is placed to filter out the ripple voltage and noises caused by the switching devices. So, it has

Manuscript received January 5, 2013; revised May 18, 2013.

This work was supported in part by Damavand Branch, Islamic Azad University.

The Authors are with Damavand Branch, Islamic Azad University, Damavand, Tehran, Iran (e-mail: babakabdi@ieee.org). to be used some high capacitive capacitors in the input and output stages of SMPSs. Due to its large capacity and low cost, electrolytic capacitors with the abilities of energy storage and voltage regulation are used for filters of SMPSs. In order to reduce the size and cost, as well as to improve the performance of the SMPSs, different ratings of electrolytic capacitors are used in the design and construction process.

The performance of the electrolytic capacitor is highly affected by its operation conditions such as voltage, current, frequency, and temperature [10]-[12]. If the electrolytic capacitor is used as a part of the LC filter, it must present a low-impedance path for the ac current and act as a constant voltage source to the load. Unfortunately, an aged electrolytic capacitor will not be able to provide a low-impedance path for the ac current and cannot be treated as a constant voltage source anymore. Therefore, it will cause the increment of the output ripple voltage. Eventually, it will cause the converter to fail in the output voltage regulation, or it may even damage the converter itself. On the other hand, among the power stage components of switching-mode power converters, electrolytic capacitors are most affected by the aging effect [13], [14]. Consequently, the electrolytic capacitor plays a very important role for the SMPS's quality and reliability, and it is very important to predict the expected lifetime of the electrolytic capacitor.

The influence of electrolytic capacitors parameters on SMPS's reliability is given in this paper. In the reliability point of view voltage derating, temperature, amount of capacitance and their paralleling effect are some important parameters which they are investigated here.

All of reliability definitions and discussions are according to MIL-HDBK-217F [15], in this paper.

\section{DEFINITION OF RELIABILITY}

The probability of proper function of a system after a time interval is referred to as its reliability.

It is dependent on the type and quality of the parts and materials used in the device, tension of each part endures and the ambient conditions which the devices are working. The failure rate in most of the electronic systems is constant, represented by $\lambda$; the reliability is expressed by:

$$
R(t)=e^{-\lambda t}
$$

The mathematical mean of $\mathrm{R}(\mathrm{t})$ occurs at:

$$
t=\frac{1}{\lambda}
$$

Which is the amount of time that should elapses until the first failure occurs. This is called the Mean Time to Failure 
(MTTF). The mean time to repair (MTTR) of the system is negligible compared to MTTF, so the mean time between failures (MTBF) of a system is expressed as:

$$
M T B F=M T T R+M T T F=\frac{1}{\lambda}
$$

The total rate of the system failure is the sum of the failure rates of all parts of the system:

$$
\lambda_{\text {system }}=\sum_{n=1}^{N} \lambda_{\text {part }}
$$

Hence, the reliability of the system will be the product of all the system components' reliabilities [9]:

$$
R_{\text {system }}=\prod R_{\text {part }}
$$

\section{RELIABILITY OF PC'S SMPSS COMPONENTS}

A case study power supply, used in PC, converts input voltage $(220 \mathrm{~V}, 50 \mathrm{~Hz}$ or $115 \mathrm{~V}, 60 \mathrm{~Hz})$ to $\pm 12,+5$ and +3.3 VDC. It also regulates them against input voltage and load variations. The output voltages can provide up to 300 watts continuously and up to 600 watts instantaneously. The case study power supply and its block diagram are shown in Fig. 1 and Fig. 2. They basically utilize from half bridge topology which stabilizes output voltages using Pulse Width Modulation (PWM) control [1].

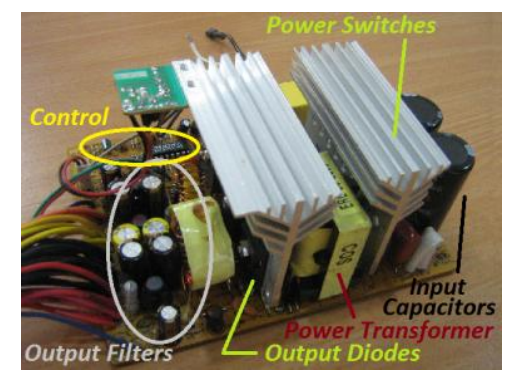

Fig. 1. PC's switch mode power supply.

In reliability calculation, there is a basic failure rate for each device. It is shown by $\lambda_{b}$. The basic failure rate is affected by quality factor of each device $\left(\pi_{Q}\right)$, stress factor $\left(\pi_{s}\right)$ which is the ratio of operational to nominal parameters (like voltage and current), temperature factor $\left(\pi_{T}\right)$ and working ambient or environmental factor $\left(\pi_{E}\right)$. There are another factors belong to specific devices. For example capacitance factor $\left(\pi_{c}\right)$ belongs to capacitors.

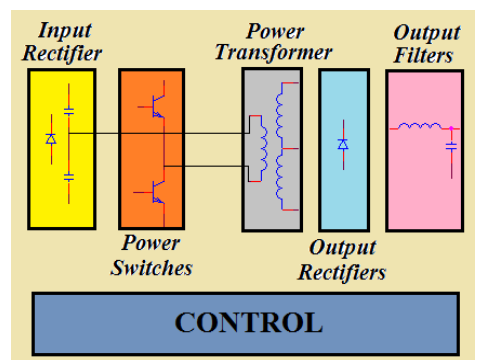

Fig. 2. Block diagram of a switch mode power supply.

According Fig. 1 and Fig. 2, a PC's SMPS compose from the following sub systems:
Input rectifier: it consists a PBU605 bridge (600V, 6A), including 4 diodes.

Input filter: Half bridge DC-DC converters utilize two serried bulk capacitors in their input. Two electrolytic capacitors $(680 \mathrm{uF}, 200 \mathrm{~V})$ are serried in this section (Fig. 2). The failure rate of these electrolytic capacitors will discuss in the next chapter.

Power switches: Half bridge converter consist two power switches. Here two power BJTs, E13009KA, are used for this aim.

Power transformer: it provides electrical insulation and converts the level of the input voltage to several values in the output.

Output rectifiers: Double schottky diodes, SB3030PT $(30 \mathrm{~A}-30 \mathrm{~V})$, are used for all of high frequency output rectifiers.

Output Filters: Each output consist a filter including two capacitors and two inductors. Two 10V, 2200UF capacitor are used in $+5 \mathrm{~V}$ output. Two $16 \mathrm{~V}, 1000 \mathrm{UF}$ capacitor are used in $+12 \mathrm{~V}$ output and two $16 \mathrm{~V}, 470 \mathrm{UF}$ capacitor are used in $-12 \mathrm{~V}$ output.

Control Circuit: Control unit includes a control IC, 60 resistors, 15 ceramic capacitors and 8 electrolytic types, 10 diodes (1n4148) and 5 transistors (2N2222).

Detail reliability calculations are given for each of mentioned subsystem in [10] and given in table 1. All relations, equations and coefficients are achieved from MIL-HDBK-217F [9].

\section{Electrolytic CAPACITORS FAILURE RATE}

Failure rate of different parts of a case study switch mode power supply are given in Table I. It is clear that the power circuitry have much failure rate than control circuit. Although the number of parts in control is more than power circuit, the failure rate of power circuit is more because of more stress and dissipation.

According MIL-HDBK-217, revision $F$, notice 2, the failure rate of electrolytic capacitors calculates as:

$$
\lambda_{c}=n \lambda_{b} \pi_{T} \pi_{C} \pi_{V} \pi_{S R} \pi_{Q} \pi_{E} f / 10^{6} h
$$

$n$ is number of the same capacitors, working in the same conditions in the system.

$\lambda_{b}$ is basic failure rate and belongs to the capacitor materials and structure. It is 0.00012 for fixed electrolytic, aluminum oxide capacitors and 0.00099 for fixed general purposed capacitors with ceramic dielectric.

$\pi_{T}$ is ambient temperature factor determines by equation (7) for both electrolytic and ceramic capacitors.

$$
\pi_{T}=\exp \left[-4061 \times\left(\frac{1}{T+273}-\frac{1}{298}\right)\right]
$$

where $T$ is ambient temperature in degree cantigrad.

$\pi_{c}$ is capacitance factor, depended to amount of capacitance, $C$. it is determines by equation (8) for electrolytic capacitors.

$$
\pi_{C}=C^{0.23}
$$


TABLE I: THE FAILURES RATE OF DIFFERENT PARTS IN PC'S SMPSS

\begin{tabular}{|c|c|c|c|c|}
\hline & & 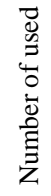 & $\begin{array}{c}\text { Each part } \\
\text { failure rate } \\
\lambda_{\text {each }}\end{array}$ & $\begin{array}{l}\text { Total failure } \\
\quad \text { rate } \\
\lambda_{\text {Total }}=n * \lambda_{\text {each }} \\
\left(\text { failures } / 10^{6} h\right)\end{array}$ \\
\hline \multirow{8}{*}{ 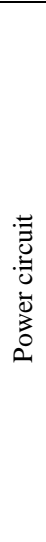 } & Input Rectifier & 4 & 0.00856 & 0.034 \\
\hline & Power Switch & 2 & 0.027 & 0.054 \\
\hline & +5V Diode & 2 & 0.008 & 0.016 \\
\hline & 12V Diode & 4 & 0.05 & 0.2 \\
\hline & Inductors & 5 & 0.012 & 0.06 \\
\hline & Power Trans. & 1 & 0.027 & 0.027 \\
\hline & Electrolytic Capacitors & \multicolumn{3}{|c|}{$\begin{array}{l}\lambda_{C}= \\
\lambda_{C i n}+\lambda_{C 5}+\lambda_{C 12}+\lambda_{C-12}\end{array}$} \\
\hline & Power stage circuit & \multicolumn{3}{|c|}{$\lambda_{\text {power }}=0.391+\lambda_{C}$} \\
\hline \multirow{7}{*}{ 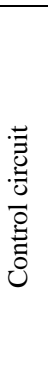 } & IC & 1 & 0.229 & 0.229 \\
\hline & resistors & 60 & 0.0035 & 0.21 \\
\hline & Ceramic Cap. & 15 & 0.015 & 0.225 \\
\hline & Electrolytic Cap. & 8 & 0.012 & 0.096 \\
\hline & Transistors & 5 & 0.0004 & 0.002 \\
\hline & Diodes & 10 & 0.026 & 0.26 \\
\hline & Control circuit & \multicolumn{3}{|c|}{$\lambda_{\text {control }}=1.022$} \\
\hline
\end{tabular}

Total system

$$
M T B F=\frac{1}{\lambda_{\text {system }}}(h / f)
$$

$\pi_{v}$ is voltage stress factor. It depends on the maximum applied voltage to nominal voltage ratio, $S$, by equation (9).

$$
\pi_{V}=\left(\frac{S}{0.6}\right)^{5}+1
$$

$\pi_{s r}$ is series resistance factor, belong to tantalum capacitors. It is unity for other kind of capacitors.

$\pi_{Q}$ is quality factor. It is 10 for commercial level capacitors.

Finally, $\pi_{E}$ is environment factor. PCs are often used in home or office which they are controlled temperature and humidity places on the ground. So, $\pi_{E}$ is unity for these kinds of devices. For the case study SMPS, shown in Fig. 1, including capacitors in input and output filters, mentioned in Section III, failure rate prediction can be calculate as follow:

Assuming ambient temperature of $35^{\circ} \mathrm{C}, \pi_{T}$ is 1.56 .

Two capacitors are serried in the input filter. The maximum input voltage is $350 \mathrm{VDC}$. So, maximum applied voltage to each capacitor is $175 \mathrm{~V}$. Considering their nominal voltage $(200 \mathrm{~V})$, their stress factor, $\mathrm{S}$, is 0.875 and $\pi_{\mathrm{V}}$ is 7.6 .

Capacitors are $680 \mathrm{uF}$, so, $\pi_{C}$ is 4.48 .

Therefore, the failure rate of input filter's capacitors can be calculating using eq. 6 as following:

$$
\begin{aligned}
& \lambda_{\text {cin }}=n \lambda_{b} \pi_{T} \pi_{C} \pi_{V} \pi_{S R} \pi_{Q} \pi_{E} \\
& =2 \times 0.00012 \times 1.56 \times 4.48 \times 7.6 \times 1 \times 10 \times 1=0.126 \mathrm{f} / 10^{6} \mathrm{~h}
\end{aligned}
$$

Two capacitors are paralleled in each output filter.

In the $+5 \mathrm{~V}$ filter, applied voltage is $5 \mathrm{~V}$. According capacitors rating $(10 \mathrm{~V}, 2200 u F), S=0.5, \pi_{V}=1.4, \quad \pi_{C}$ $=5.87$, its failure rate can be calculates as:

$$
\begin{aligned}
& \lambda_{c 5}=n \lambda_{b} \pi_{T} \pi_{C} \pi_{V} \pi_{S R} \pi_{Q} \pi_{E} \\
& =2 \times 0.00012 \times 1.56 \times 5.87 \times 1.4 \times 1 \times 10 \times 1=0.03 \mathrm{f} / 10^{6} \mathrm{~h}
\end{aligned}
$$

For $+12 \mathrm{~V}$ filter, capacitors are $16 \mathrm{~V}, 1000 \mathrm{uF}$, so, $S=0.75, \pi_{V}$ $=4.05, \pi_{C}=4.89, \lambda_{c 12}=0.074 \mathrm{~F} / 10^{6} \mathrm{~h}$.

In the $-12 \mathrm{~V}$ filter, capacitors are $16 \mathrm{~V}, 470 u F$, so, $S=0.75$, $\pi_{V}=4.05, \pi C=4.11, \lambda_{c-12}=0.062 f / 10^{6} \mathrm{~h}$.

Finally failure rate of filter's electrolytic capacitors is:

$$
\lambda_{C}=\lambda_{\text {Cin }}+\lambda_{C 5}+\lambda_{C 12}+\lambda_{C-12}=0.291 \mathrm{f} / 10^{6} \mathrm{~h}
$$

With this amount of capacitor failure rate, the SMPS's total failure rate is:

$$
\lambda_{\text {system }}=1.413+0.291=1.7 \mathrm{f} / 10^{6} \mathrm{~h}
$$

\section{DISCUSSION}

It can be seen that in the case study SMPS, about $17.1 \%$ of total failure rate belongs to the filter's electrolytic capacitors, which is considerable.

According equations (6) to (9) it is clear that the failure rate of capacitors is depended to ambient temperature, capacitance and voltage stress.

The relation between ambient temperature and electrolytic capacitors failure rate is shown in Fig. 3. Considering PC's ambient temperature and power supply dissipations, the ambient (or capacitor case) temperature of elements in a PC's SMPS varies between 25 and 45 degree centigrade. According Fig. 3 the failure rate of electrolytic capacitors varies between 1 and 2.35 in the mentioned temperature range. So, good thermal design like fan blowing and avoiding physical contact between capacitors and dissipative devices, such as heat-sinks and hot inductors, can improve the reliability.

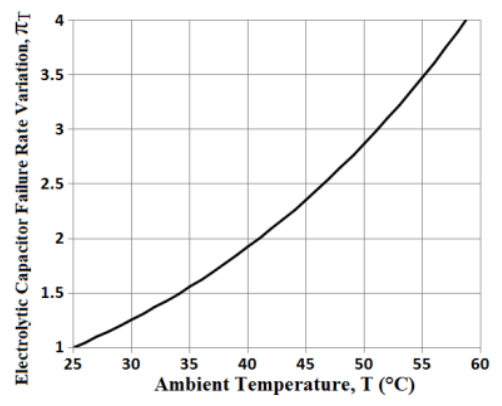

Fig. 3. Electrolytic capacitors failure rate variation versus ambient temperature.

Elements ambient temperature can be varies more than 35 to $50^{\circ} \mathrm{C}$, depends on thermal design. In this range of 
temperature variation $\pi_{T}$ varies from 1.56 to 2.9 which causes electrolytic capacitors failure rate variations from 0.291 to o.56. This variation of capacitors failure rate causes variation of total system failure rate from 1.7 to 1.97 failures per million hours which means $15.8 \%$ more failures. Briefly, $15^{\circ} \mathrm{C}$ of temperature variations in electrolytic capacitors ambient, which arises from thermal design, causes $15.8 \%$ less life time.

The second effective parameter in capacitor's life time is capacitance factor. SMPS designer uses two or more paralleled small electrolytic capacitor instead off one bulk capacitor for equivalent series resistance (ESR) and equivalent series inductance (ESL) minimization. But it will be shown here that it can be decrease life time of the converter. ESR and ESL can be developed by paralleling one some nano-farad ceramic or other kind of capacitors which almost effective less on the reliability.

Electrolytic capacitors failure rate variation versus Capacitance is shown in Fig. 4.

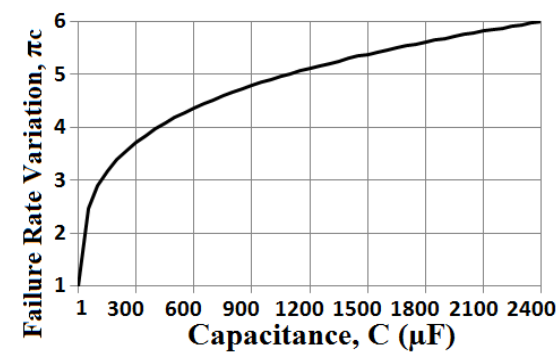

Fig. 4. Electrolytic capacitors failure rate variation versus Capacitance.

In the case study power supply two parallel capacitor are used in all of output filters. In the $+12 \mathrm{~V}$ output filter, the failure rate of two $1000 u F$ capacitor is $\lambda_{c 12}=0.074 F / 10^{6} \mathrm{~h}$. The failure rate of a $2000 u F, 16 \mathrm{~V}$ capacitor is $0.043 \mathrm{~F} / 106 \mathrm{~h}$. The failure rate of a $220 n F, 50 \mathrm{~V}$ is $0.0143 F / 106 h$. The total failure rate of a $2000 \mathrm{uF}$ and a $220 n F$ is $0.0573 F / 106 h$ which is $23 \%$ less than two paralleled $1000 \mathrm{uF}$ capacitor.

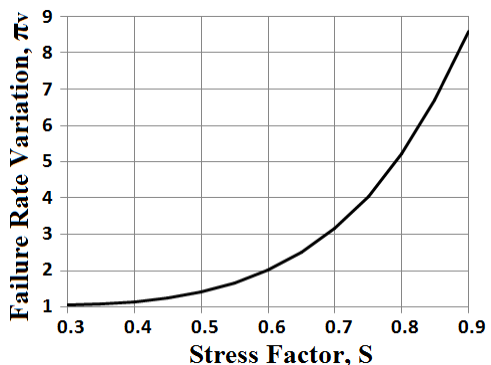

Fig. 5. Electrolytic capacitors failure rate variation versus stress factor.

The final effective parameter on the electrolytic capacitors life time is voltage stress factor. Stress factor is defined by maximum applied voltage to device nominal voltage. Nominal voltage of device has to be more than its applied voltage for this factor deactivation. In the other word, nominal parameters of device have to be derated. For example, maximum applied voltage to an electrolytic capacitor, at least, has to be less than 0.9 of its nominal voltage, or electrolytic capacitors have to be derated minimum 0.9 of their nominal voltage. Derating factor defines the stress factor, which its effect on electrolytic capacitors is shown in Fig. 5.
For example, in the $+5 \mathrm{~V}$ output filter of case study SMPS, two $2200 u F, 10 \mathrm{~V}$ capacitor is used. Designers can be use $2200 u F, 6.3 V$ for frugality. In this case $S=0.793, \pi_{V}=5.05$, $\lambda_{c 5}=0.107 \mathrm{~F} / 10^{6} \mathrm{~h}$. In the other word failures will increase $256 \%$ instead of some cent frugality.

According Fig. 5, voltage stress factor increases to more than 2 when voltage derating is less than 0.5 . Therefore, choosing capacitors with nominal voltage twice of maximum applied voltage is recommended in the reliability point of view. Off course, in high voltage capacitors conciliation between economy and reliability has to be concerned.

\section{CONCLUSION}

The effect of electrolytic capacitors life time on the reliability of a PC's SMPS has been discussed in this paper. It is shown that they play a significant role on the SMPS's lifetime. Electrolytic capacitors decrease PC's life time about $17.1 \%$. Different effective parameters on the electrolytic capacitors life time, like ambient temperature, capacitance and voltage stress factor have been discussed carefully.

It was shown that thermal design of SMPSs is a significant stage in the design process. It was shown that $15^{\circ} \mathrm{C}$ temperature rise in electrolytic capacitors ambient, which arises from thermal design, causes $15.8 \%$ less life time for electrolytic capacitors.

It was also recommended to parallel a some nano-farad ceramic capacitor instead of paralleling two same electrolytic capacitor for ESR and ESL development.

Finally, choosing capacitors with nominal voltage twice of maximum applied voltage is recommended in the reliability point of view.

\section{REFERENCES}

[1] A. Pressman, Switching Power Supply Design, 2nd ed. McGraw-Hill, 1998.

[2] B. Abdi, M. B. Menhaj, L. Yazdanparast, and J. Milimonfared, "The effect of the transformer winding on the reliability of switching power supplies," in Proc. IEEE EPE-PEMC Conf., 2006

[3] Y. M. Chen, H. C. Wu, M. W. Chou, and K. Y. Lee, "Online failure prediction of the electrolytic capacitor for LC filter of switching-mode power converters," IEEE Trans. on Industrial Electronics, Jan. 2008.

[4] C. Rodriguez and G. A. J. Amaratunga, "Long-lifetime power inverter for photovoltaic AC modules," IEEE Trans. on Industrial Electronics, July 2008.

[5] F. Chan and H. Calleja, "Design strategy to optimize the reliability of grid-connected PV systems," IEEE Trans. on Industrial Electronics, vol. 56, no. 11, November 2009.

[6] A. H. Ranjbar, B. Abdi, S. A. Nabavi Niak, G. B. Gharehpetian, and J. Milimonfared, "Reliability comparison of Fuel-Cell DC-DC converter in two cases of using IPM Switch and paralleling MOSFETs," in Proc. International Symposium on Power Electronics, Electrical Drives, Automation and Motion, SPEEDAM, 2008.

[7] B. Abdi, A. H. Ranjbar, J Milimonfared, and G. B. Gharehpetian, "Reliability comparison of boost PFC converter in DCM and CCM operating modes," in Proc. International Symposium on Power Electronics, Electrical Drives, Automation and Motion, SPEEDAM, 2008.

[8] B. Abdi, A. H. Ranjbar, G. B. Gharehpetian, and J. Milimonfared, "Reliability considerations for parallel performance of semiconductor switches in high power switching power supplies," IEEE Trans. on Industrial Electronics, vol. 56, no. 6, June 2009.

[9] M. Askari and B. Abdi, "Reliability investigation of PC's SMPSs," WSEAS, CSECS'10, Athens, 2010.

[10] Jr. S. Parler, "Improved spice models of aluminum electrolytic capacitors for inverter applications," IEEE Trans. Ind. Appl., vol. 39, no. 4, pp. 929-935, Jul./Aug. 2003. 
[11] M. Gasperi, "Life prediction modeling of bus capacitors in AC variable frequency drives," IEEE Trans. Ind. Appl., vol. 41, no. 6, Nov./Dec. 2005.

[12] T.-Y. Chang, X. Wang, D. Evans, S. Roberson, and J. Zheng, "Characterization of tantalum oxide-ruthenium oxide hybrid capacitor," IEEE Trans. Ind. Electron., vol. 51, no. 6, pp. 1313-1317, Dec. 2004.

[13] G. Chen, R. Burgos, Z. Liang, F. Lacaux, F. Wang, J. Wyk, W. Odendaal, and D. Boroyevich, "Reliability-oriented design considerations for highpower converter modules," in Proc. IEEE Power Electron. Spec. Conf., 2004.

[14] P. Venet, H. Darnand, and G. Grellet, "Detection of faults of filter capacitors in a converter. Application to predictive maintenance," in Proc. IEEE Int. Telecommun. Energy Conf., 1993.

[15] "Reliability Prediction of Electronic Equipment," MIL-HDBK-217F, notice 2, 1995.

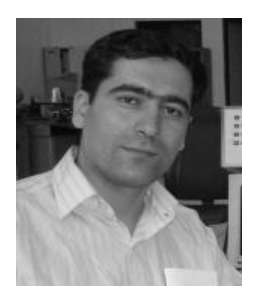

Babak Abdi was born in Tehran in 1976. He received his M.S. and Ph.D. degree in electrical engineering in 2005 and 2009 from Amirkabir University of Technology (Tehran Polytechnic), Tehran, Iran, respectively. He is currently a member of IEEE and a faculty member of Damavand branch, Islamic Azad University, Tehran, Iran. His research interests include power electronics, application of reliability in power electronics, Electromagnetic Interferences (EMI), and electrical machines and drives.

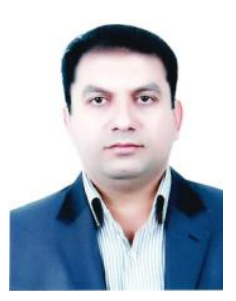

Reza Ghasemi was born in Tehran, Iran in 1979. He received his B.Sc. degree in Electrical engineering from Semnan University in 2000. He received the M.Sc. and the Ph.D. degree in control engineering from Amirkabir University of Technology, Tehran, Iran in 2004 and 2009, respectively. His research interests include large-Scale Systems, adaptive control, robust control, nonlinear control, and intelligent systems. Reza Ghasemi joined the Department of Electrical Engineering, Damavand Branch, Islamic Azad University, Tehran, Iran, where he is currently an assistant professor of electrical engineering.

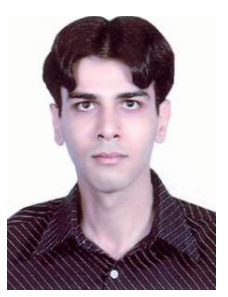

Sayyed Mohammad Mehdi Mirtalaei was born in Shahreza-Isfahan, Iran in 1983. He received his B.S. degree in electrical engineering from Isfan University of Technology, Iran in 2005. He received his M.S. and $\mathrm{Ph} . \mathrm{D}$. in electrical engineering from Amirkabir University of Technology, Tehran, Iran in 2007 and 2012 respectively. His research interest are power electronics, EMI/EMC and numerical method in electromagnetic. 